\title{
THE EFFECT OF in-situ GROWN Pueraria phaseoloides ON NUTRIENT STATUS OF COCONUT-GROWN SOILS AND COCONUT YIELD IN LOW COUNTRY WET ZONE OF SRI LANKA
}

\author{
KVNN Jayalath and KB Dassanayake \\ Coconut Research institute, Lunuwila
}

Despite the promise of organic mar ures in enhancing/maintaining fertility and productivity of soils devoted for perennial crops like coconuts, its adoption by farmers is low mainly due to their lack of availability in required quantities. In-situ cultivation and incorporation of green manure crops is increasingly being considered as a viable alternative for ex-situ organic manure. This study analyses the effect of in-situ grown Pueraria phaseoloides on nutrient status of coconut-grown soils and on coconut yield in low country Wet Zone of Sri Lanka. The treatments were without Pueraria cover with recommended inorganic fertilizer application to coconut palms, growing Pueraria with recommended inorganic fertilizer application to coconut palms and growing Pueraria without nitrcgen fertilizer application to coconut palms. The nitrogen, phosphorous and potassium content in the soil where Pueraria was grown was significantly higher than in soil without Puereria cover irrespective of the nitrogen fertilizer application. Higher organic matter content, cation exchange capacity, water holding capacity and ideal soil $\mathrm{pH}$ for the growth of coconut palm were observed in Pueraria grown soil. The results revealed that the in-situ cultivation and appication of Pueraria positively affected coconut yield. 